\title{
METHODOLOGY TO ESTIMATE THE MAXIMUM DEPTH OF RELIABILITY OF TWO-DIMENSIONAL GEOELECTRICAL MODELS DERIVED FROM MAGNETOTELLURIC DATA
}

\author{
Andréa Cristina Lima dos Santos ${ }^{1,2 *}$, Antônio Lopes Padilha², Icaro Vitorello², \\ Marcelo Banik de Pádua² and Augusto César Bittencourt Pires ${ }^{1}$
}

\begin{abstract}
An empirical technique is proposed to estimate the maximum depth of reliability of two-dimensional (2D) geoelectrical models derived from magnetotelluric surveys conducted in regions with different conductivity. The results are then compared to those derived from a heuristic methodology well established in the literature. Experimental data from a linear profile cutting across the major structures in the SE portion of the Borborema Province, northeastern Brazil, are used. The data were collected with modern instrumentation, processed by robust techniques and modeled using inversion algorithms available nowadays to the research community of electromagnetic induccion inside the Earth. Sensitivity tests have shown that the 2D geoelectrical section is robust and accurately represents the conductivity distribution below the profile. The 2D section is used as a starting point for the empirical method employed, which consists of introducing a perfect conductor (or resistor) at different depths of the 2D model. The effect of adding this structure to the data fitting is checked through forward calculation and by comparing the RMS misfit. The results show that the maximum depth of reliability of the 2D geoelectrical model is usually given by the phase of the transverse electric (TE) mode, whereas the maximum depth of propagation of the EM signal is usually given by the phase of transverse magnetic (TM) mode. The empirical approach shows similar variations in depth when compared to the results from a heuristic method, but provides lateral variations more compatible with the diffusive process of EM wave propagation.
\end{abstract}

Keywords: magnetotelluric soundings, two-dimensional geoelectrical model, maximum depth of reliability of geoelectrical model.

RESUMO. Uma técnica empírica para estimar a profundidade máxima de confiabilidade de modelos geoelétricos bidimensionais (2D), obtidos a partir de sondagens magnetotelúricas realizadas em regiões de diferentes condutividades, éaqui proposta e seus resultados são comparados àqueles derivados de uma metodologia heurística já consagrada na literatura. Para tanto, são utilizados dados experimentais obtidos em um perfil linear que corta transversalmente as principais estruturas e terrenos na porção SE da Província Borborema, região Nordeste do Brasil. Os dados utilizados foram coletados com instrumentação moderna, processados por técnicas robustas e modelados por algoritmos de inversão atualmente disponíveis para a comunidade de estudos de indução eletromagnética no interior da Terra. A seção geoelétrica 2D derivada desse procedimento é robusta em relação a diferentes testes de sensibilidade e representa adequadamente a distribuição de condutividade elétrica sob 0 perfil, sendo aqui utilizada como ponto de partida para o método empírico empregado. A técnica empírica aqui proposta é bastante simples, baseada na introdução de um condutor (ou um resistor) perfeito em diferentes profundidades do modelo de distribuição de condutividades e verificando seu efeito no ajuste dos dados (RMS) por cálculo direto usando o programa empregado na inversão dos dados. Os resultados obtidos mostram que a profundidade limite de validade da interpretação 2D do modelo geoelétrico é geralmente dada pela fase do modo transverso elétrico (TE) de propagação do sinal eletromagnético (EM), enquanto o limite máximo de propagação desse sinal é dado pela fase do modo transverso magnético (TM). Em comparação com as profundidades de investigação obtidas pelo método heurístico, a metodologia empírica mostra comportamento semelhante nas variações de profundidade, mas fornece variações laterais mais compatíveis com o processo difusivo de propagação das ondas EM.

Palavras-chave: sondagem magnetotelúrica, modelo geoelétrico bidimensional, profundidade máxima de confiabilidade do modelo.

\footnotetext{
${ }^{1}$ Universidade de Brasília, Instituto de Geociências, Laboratório de Geofísica Aplicada (LGA), Campus Universitário Darcy Ribeiro, ICC, Ala Central, Asa Norte, 70910-900 Brasilia, DF, Brazil. Phone: +55(61) 3107-6988 - E-mails: andrealima@unb.br; pires@unb.br

2 Instituto Nacional de Pesquisas Espaciais, Divisão de Geofísica Espacial (DGE), Av. dos Astronautas, 1.758, Jardim da Granja, 12227-010 São José dos Campos, SP, Brazil. Phone: +55(12) 3208-7845; Fax: +55(12) 3208-7898 - E-mails: andrea.lima@dge.inpe.br; padilha17@gmail.com; icaro@dge.inpe.br; marcelo.banik@gmail.com

*Current address.
} 


\section{INTRODUCTION}

The depth of investigation of a geophysical survey, from a practical point of view, depends on several factors, such as the sensitivity and accuracy of the instruments, the complexity of the geological section and the noise level inherent to the experimental measurements (Spies, 1989). For electromagnetic methods (EM), different heuristic techniques have been developed to estimate the subsurface survey depth (Niblett \& Sayn-Wittgenstein, 1960; Bostick, 1977; Parker, 1982; Spies, 1989; Reid \& Macnae, 1999). All these techniques have in common the concept of skin depth, which is related to the concepts of propagation and damping of a plane wave of the electromagnetic field in a conductive medium.

The magnetotelluric method (MT) is used to determine subsurface geoelectrical structures through simultaneous measurements on the Earth's surface of the natural variations of the electric and magnetic fields in a wide range of frequencies (typically from 0.0001 to $1000 \mathrm{~Hz}$ ). Knowing the typical values of electrical conductivity of rocks, the use of this method within this frequency range allows inferring conductivity distribution from the first meters of the crust downward to hundreds of kilometers in the upper mantle.

The interpretation of any large-scale MT survey, which crosses geological sections with significant variations in electrical conductivity, naturally raises issues related to the depth of the investigation. To interpret these data it is necessary to consider that the penetration of the EM signal, and consequently, the geophysical information embedded in the field data can differ significantly for the same frequency in different surveys. Typically, surveys in regions with high conductivity in the upper crust (the case of sedimentary basins) will have their signal highly attenuated, even at low frequencies, when compared to other regions with more resistive upper crust (the case of outcrops of crystalline rocks). The main consequence of the difference in damping is the ability to extract more reliable geophysical information in resistive regions than in conductive regions when disregarding other distortional effects on the EM signals. For a semiquantitative understanding of the structures modeled in a greater depths by MT surveys, several studies estimate the maximum depth of reliability of the model in different parts of the profile from the maximum penetration of the EM signal under each of the stations as derived by heuristic techniques (see Ferguson et al., 2005; Hamilton et al., 2006).

This work proposes a new empirical technique to estimate the maximum depth of reliability of a geoelectrical model obtained by two-dimensional (2D) inversion of MT soundings in regions with different conductivity. The results are compared to those derived from a heuristic methodology already established in the literature. Experimental data from a linear profile cutting across the major structures in the SE portion of the Borborema Province, northeastern Brazil, are used. These data were collected and processed using modern instrumentation and modeled with the techniques currently available for the studies of electromagnetic induction in the Earth's interior. The 2D geoelectrical section derived from this procedure is robust with respect to different sensitivity tests and properly represents the distribution of electrical conductivity under the profile, and it is used as the starting point for the empirical method applied.

\section{DEPTH OF INVESTIGATION IN THE MAGNETOTELLURIC METHOD}

The penetration of the EM signals inside the Earth depends on its oscillation period and the medium resistivity. The penetration depth of these signals is expressed by the skin depth $(\delta)$, calculated as the depth at which the amplitude of the natural signal is reduced in 1/e (approximately $37 \%$ ) of its initial surface value. For a homogeneous half-space it is given by:

$$
\delta=\sqrt{\frac{2}{\omega \mu \sigma}} \approx 500 \sqrt{\rho T}
$$

where $\sigma$ is the conductivity of the medium; $\omega$ is the angular frequency; $\mu$ is the magnetic permeability; $\rho$ is the resistivity of the medium; and $T$ is the period.

Thus, the electromagnetic waves penetrate to greater depths for lower frequencies and/or rocks with lower conductivity. In practice, however, skin depth is used only as a reference for the damping that the electromagnetic signals undergo when they propagate in a conductive medium, since the Earth's interior is not a homogenous half-space. Consequently, alternative techniques must be used to estimate the maximum depths of reliability of the geoelectrical models derived from experimental data on electrical conductivity distribution.

\section{Magnetotelluric method}

MT is a geophysical method for determining the distribution of electrical conductivity inside the Earth from the interpretation of simultaneous measurements, carried out on the surface, of the natural temporal variations of the geomagnetic and geoelectrical induced fields. An impedance tensor $(Z)$ relates the complex horizontal components of the electric $(E x, E y)$ and magnetic $(H x, H y)$ fields, in mutually orthogonal directions at a given frequency $(\omega)$, in a single measurement site. The relationship 
between each term is determined by the equation:

$$
\left(\begin{array}{c}
E_{X}(\omega) \\
E_{Y}(\omega)
\end{array}\right)=\left(\begin{array}{ll}
Z_{x x} & Z_{x y} \\
Z_{y x} & Z_{y y}
\end{array}\right)\left(\begin{array}{l}
H_{X}(\omega) \\
H_{Y}(\omega)
\end{array}\right) .
$$

Thus, a linear system is defined for each frequency as:

$$
\begin{aligned}
& E_{x}=Z_{x y} H_{y}+Z_{x x} H_{x} \\
& E_{y}=Z_{y x} H_{x}+Z_{y y} H_{y} .
\end{aligned}
$$

In 2D situations, where the conductivity varies with depth and along one of the horizontal directions, the electric and magnetic fields can be decomposed into a rotated axis system, with the main impedance values, $Z_{x y}^{\prime}$ and $Z_{y x}^{\prime}$, calculated with the axes parallel and perpendicular to the strike of the 2D structure. If the geology can be effectively represented by the 2D model, $Z_{x x}^{\prime}$ and $Z_{y y}^{\prime}$ are zero and the tensor relationship (Eq. (3)) becomes:

$$
\begin{aligned}
& E_{x}=Z_{x y}^{\prime} H_{y} \\
& E_{y}=Z_{y x}^{\prime} H_{x} .
\end{aligned}
$$

In this situation, the propagation of the electromagnetic wave inside the Earth can be separated in two modes, transverse electrical (TE, where the electric field is projected parallel to the strike of the geoelectrical structures) and transverse magnetic (TM, where the electrical field is perpendicular to strike). From these rotated impedances, the apparent resistivity and phase

$$
\begin{gathered}
\rho_{a x y}=\frac{\left|Z_{x y}^{\prime}\right|}{\omega \mu} \quad \rho_{a y x}=\frac{\left|Z_{y x}^{\prime}\right|}{\omega \mu} \\
\phi_{x y}=\tan ^{-1}\left(\frac{\operatorname{Im}\left(Z_{x y}^{\prime}\right)}{\operatorname{Re}\left(Z_{x y}^{\prime}\right)}\right) \quad \phi_{y x}=\tan ^{-1}\left(\frac{\operatorname{Im}\left(Z_{y x}^{\prime}\right)}{\operatorname{Re}\left(Z_{y x}^{\prime}\right)}\right)
\end{gathered}
$$

can be calculated for a wide range of frequencies, using the Fourier transform components of the time series of the measured magnetic and electric fields. These expressions together with the skin depth (Eq. (1)), provide the means to explore the conductivity distribution inside the Earth.

An MT survey provides curves of apparent resistivity and phase as a function of frequency, which are subsequently inverted to provide conductivity variation as a function of depth. This procedure compares the transference function results generated by models, generally 2D and 3D. The model parameters (depth and resistivity of different layers) are modified until a model composed of possible conductivity structures that would originate the values measured on the surface is found. Further details on the MT method can be found in Simpson \& Bahr (2005).

\section{Heuristic methodology: Niblett-Bostick transform}

The Niblett-Bostick transform (Niblett \& Sayn-Wittgenstein, 1960; Bostick, 1977), originally developed to estimate the distribution of resistivity with depth is, currently, the most used heuristic technique to estimate the maximum penetration depth of the MT signals and consequently, the depth of interpretation depths of the geoelectrical models (recent examples in the literature include Evans et al., 2011; Dennis et al., 2011; Miensopust et al., 2011). This transform gives the distribution of resistivity as a function of depth $\left(\rho_{N B}(h)\right)$, where $h$ is the penetration depth of the EM signal in a homogeneous half-space of apparent resistivity $\left(\rho_{a}\right)$ for a given frequency (period) (Jones, 1983). This depth is defined as:

$$
h=\sqrt{\frac{\rho_{a}(T) T}{2 \pi \mu_{0}} .}
$$

The resistivity values associated with this depth are obtained by:

$$
\rho_{N}(h)=\left|\rho_{a}\right| \frac{1+m(T)}{1-m(T)},
$$

where:

$$
m(T)=\frac{d \log \left(\left|\rho_{a}\right|\right)}{d \log (T)},
$$

or:

$$
\rho_{B}(h)=\left|\rho_{a}\right|\left(\frac{\pi}{2 \varphi}-1\right) .
$$

It is noteworthy that this penetration depth implies an attenuation factor of approximately $1 / 2$, instead of attenuation factor $1 / \mathrm{e}$ commonly used for skin depth. In the equations above $\rho_{N}$ and $\rho_{B}$ are, respectively, Niblett (Niblett \& Sayn-Wittgenstein, 1960) and Bostick resistivity (Bostick, 1977). Note that $\rho_{N}$ is obtained exclusively from the apparent resistivity module whereas $\rho_{B}$ is obtained by using both the phase and the apparent resistivity module.

It should be noted that this transformation is not a precise depth conversion, and it is formally applicable only in one dimensional situations (1D, where medium resistivity changes with depth only) or in situations in which the MT responses can be approximated as 1D. In more complex geological situations (where resistivity varies with depth and horizontally), the method is valid only when the two propagation modes of the electromagnetic wave (TE and TM) are completely decoupled and penetrate to the same depths of the signals in 1D structures (Jones, 2006).

\section{Empirical methodology: effect of a perfect conductor at great depths}

According to Berdichevsky \& Dmitriev (2002), the best approach to evaluate the maximum depth of an MT survey was suggested 
by Parker (1982). It is based on determining the deepest depth at which the insertion of a perfect and unlimited conductor in a resistivity profile has a detectable effect on MT data.

Based on this hypothesis, we established a search strategy to find the deepest depth of sensitivity of a subsurface resistivity model to the experimental data. The procedure used consisted of the insertion of an unlimited perfect conductor in the base of a 2D model, derived from the inversion of the experimental data, and perform a forward calculation to verify the effect of this conductor on the theoretical curves generated by the model. The procedure is repeated for different depths of the perfect conductor to search the depth at which the conductor is sensed by the data. This depth is determined comparing the fitting of the experimental data to the theoretical data produced by the model (root mean square - RMS). The experimental data are insensitive to a given depth when the RMS is the same as in the model derived from the $2 \mathrm{D}$ inversion of the data (without the conductor). On the other hand, the deepest of depth sensitivity of the model to the experimental data is given by the depth at which the RMS starts to increase when the conductor is inserted. Alternatively, in the case of a region with high electrical conductor on the mid-upper crust (Jatobá Basin), we also tested the effect of inserting a perfect resistor under some stations of the analyzed profile.

\section{AVAILABLE EXPERIMENTAL DATA}

The used data were generated from a MT survey carried out in the SE portion of the Borborema Province, northeastern Brazil. This region, originally characterized by Almeida et al. (1981), was defined as complex mosaic of amalgamated crustal blocks. It is a consequence of geological processes that were finalized in the Brasiliano/Panafricano Orogeny (700 to $450 \mathrm{Ma}$ ), which consisted of a series of tectonic-orogenic events, triggered at the end of the Neoproterozoic, that formed lithostructural units of magmatic and metamorphic rocks consolidated at the top of the crust. Massive granitoid plutonism and major shear zones from the Neoproterozoic/Brasiliano are characteristic of this area (Medeiros, 2004). The MT survey is positioned on the Alto Moxotó and Pernambuco-Alagoas terrains, separated by the Pernambuco shear zone; the Sergipano Belt (Poço Redondo, Canindé, Marancó and the Macururé subdomains) and cuts perpendicularly the Jatobá sedimentary basin (Fig. 1).

In this SSE-NNW profile of approximately 260-km long, 23 soundings were conducted. The data were processed with robust techniques (Egbert, 1997) and the geoelectrical strike dimension and direction were estimated using invariant techniques (Bahr, 1988) and tensor decomposition (Groom \& Bai- ley, 1989). The strike direction was dominantly N70E, parallel to the main geological structures, while data for a significant number of the stations presented a $2 \mathrm{D}$ behavior. The $2 \mathrm{D}$ REBOCC code for inversion of the MT data was used to obtain a smooth model of the subsurface conductivity distribution (Fig. 2). The code is based on a variant of the OCCAM algorithm (Groot-Hedlin \& Constable, 1989), in which the solution of the non-linear inversion is obtained in the model parameter space of the model by the Gauss-Newton method. Techniques of space reduction are used (REBOCC, Siripunvaraporn \& Egbert, 2000) to solve the resulting system of linear equations. The obtained model fitted well the experimental data $(R M S=3.6)$.

\section{DEPTH OF INVESTIGATION Results of the heuristic techniques}

An approximation of the maximum depth of investigation was estimated by the Niblett-Bostick transform, using Eq. (6) and taking into account the apparent resistivity of the maximum period measured at each station. The results are shown in Figure 3, where two depths for each station are obtained and refer to the two modes of EM wave propagation, TE and TM.

Generally, the penetration depth is higher for TM mode than for the TE mode. Jones (2006) has already observed that this fact can be explained by the more attenuated propagation of the EM wave when the electric field is parallel (TE mode) to the direction of maximum conductivity. The consequence is that the TE mode generally requires longer periods to penetrate to same depth as the TM mode.

The presence of conductive structures in the upper crust is a strong factor in the damping of the EM signals. The conductor between the stations $07 \mathrm{~b}$ and $08 \mathrm{c} \mathrm{limits} \mathrm{the} \mathrm{penetration} \mathrm{of} \mathrm{the} \mathrm{sig-}$ nal significantly, which is confined at these stations to a depth of 10-30 km. The EM signal at the SE and NW edges of the profile, especially in the TM mode, penetrate beyond the maximum depth displayed in the model.

\section{Results of the empirical technique}

Figures 4 to 6 illustrate the procedure used to derive the deepest depth of sensitivity of the model to the experimental data using the proposed empirical technique.

Figure 4 shows the 2D model given by the inversion of the MT data (Fig. 2) with a high conductivity body (resistivity of $10^{-8}$ ohm.m, considered as perfect conductor) inserted from $30 \mathrm{~km}$ deep. Figure 5 illustrates the result when this conductor is inserted in the model, by comparing the theoretical curves 


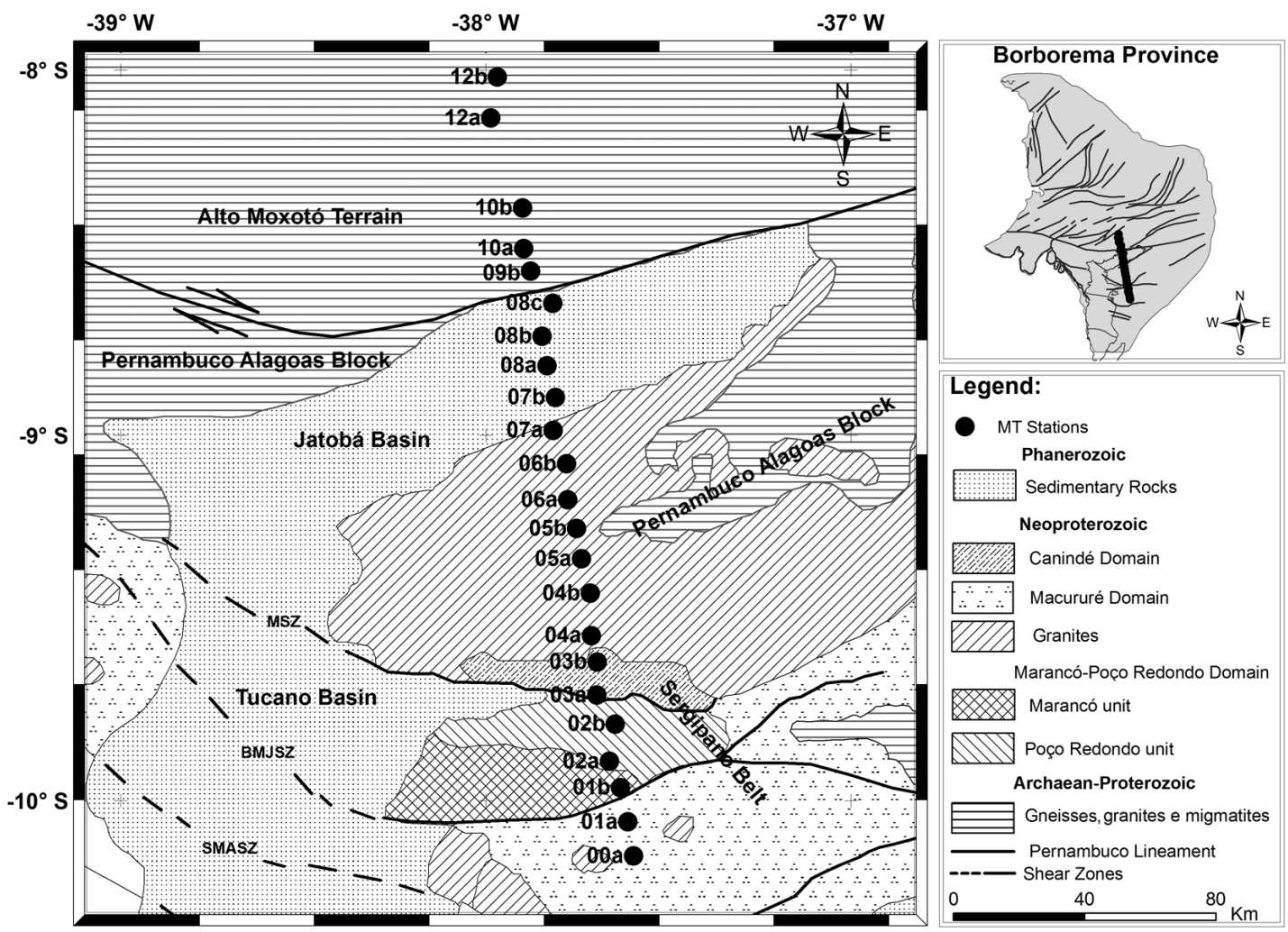

Figure 1 - Simplified geology of the SE portion of the Borborema Province and the localization of the MT stations. The Marancó-Poço Redondo domain is separated into two subdomains. MSZ, BMJSZ and SMASZ are, respectively, the Macururé, Belo Monte-Jeremoabo and São Miguel do Aleixo shear zones (modified from Oliveira et al., 2010).

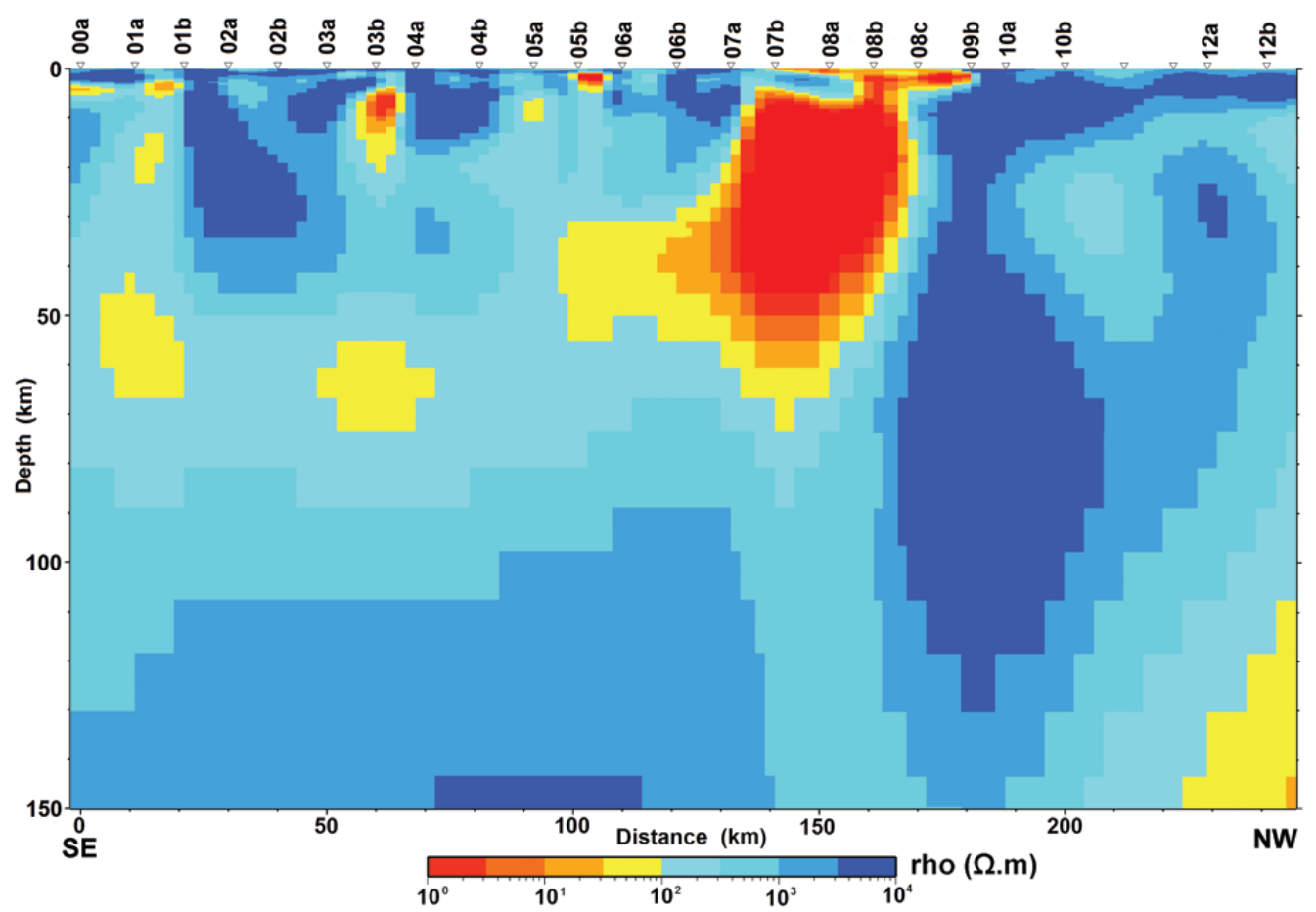

Figure 2-2D resistivity model derived from the inversion of the MT profile data for the SE portion of the Borborema Province (Santos, 2012). 


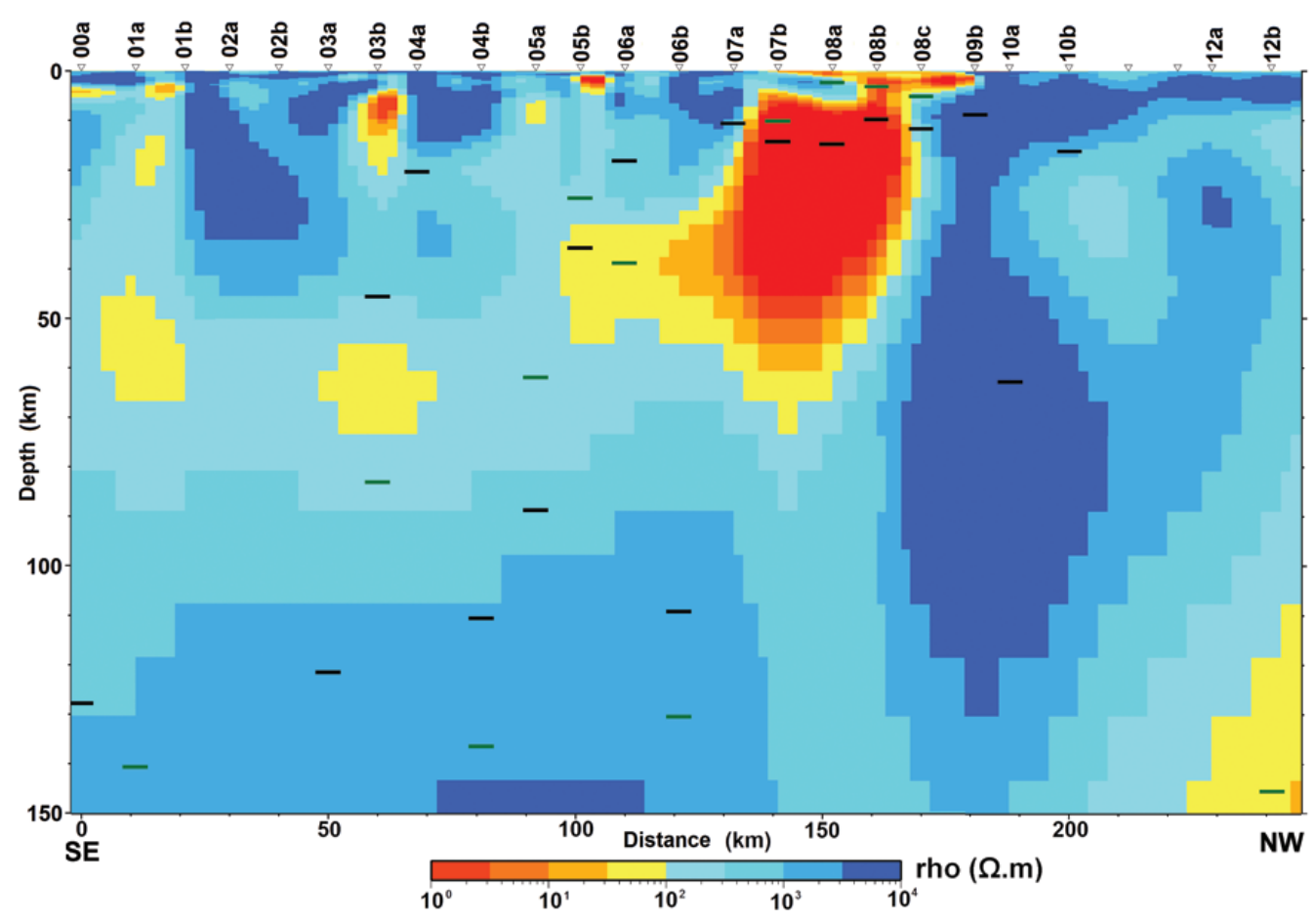

Figure 3 - Maximum depth given by the heuristic technique for each MT station, overlaid to the 2D resistivity model of the Borborema Province. The black (TE mode) and green (TM mode) traces below each station show the maximum depth given by the Niblett-Bostick transform (Eq. (6)). The lack of traces below some stations show that penetration depth of the signal is greater than $150 \mathrm{~km}$.

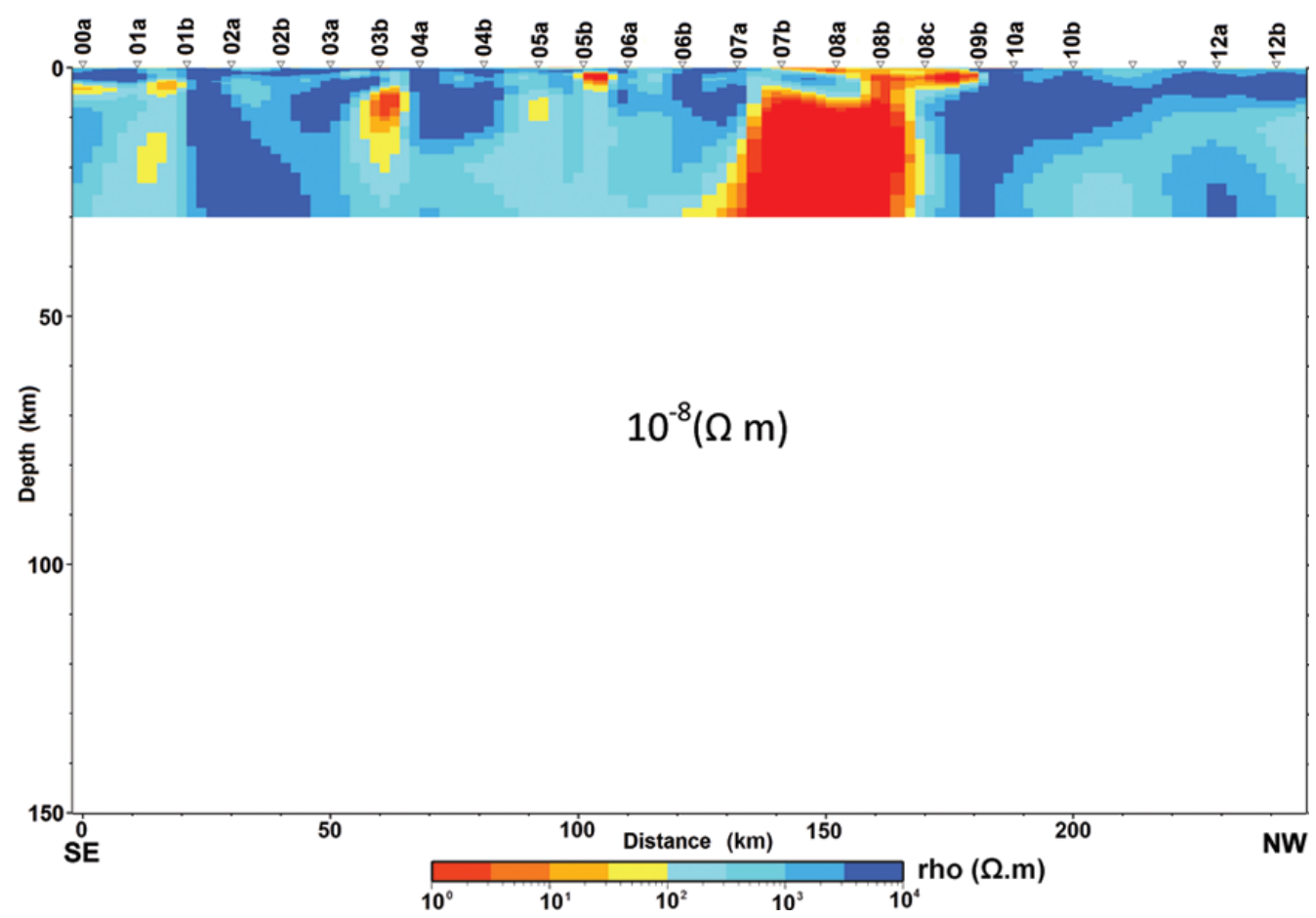

Figure 4-2D resistivity model of Figure 2, overlaid by a perfect conductor body from $30 \mathrm{~km}$ depth. 


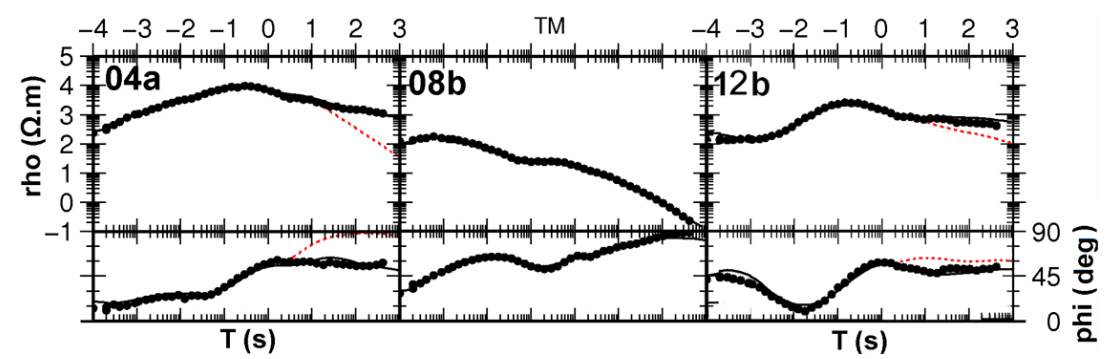

Figure $\mathbf{5}$ - Comparison of apparent resistivity and phase theoretical curves with the experimental data in the TM mode for 3 stations of the SE Borborema profile. The dots are the experimental data, the solid line is the theoretical result given by the model of Figure 2 and the red dashed line is the theoretical result given by the model of Figure 4 .

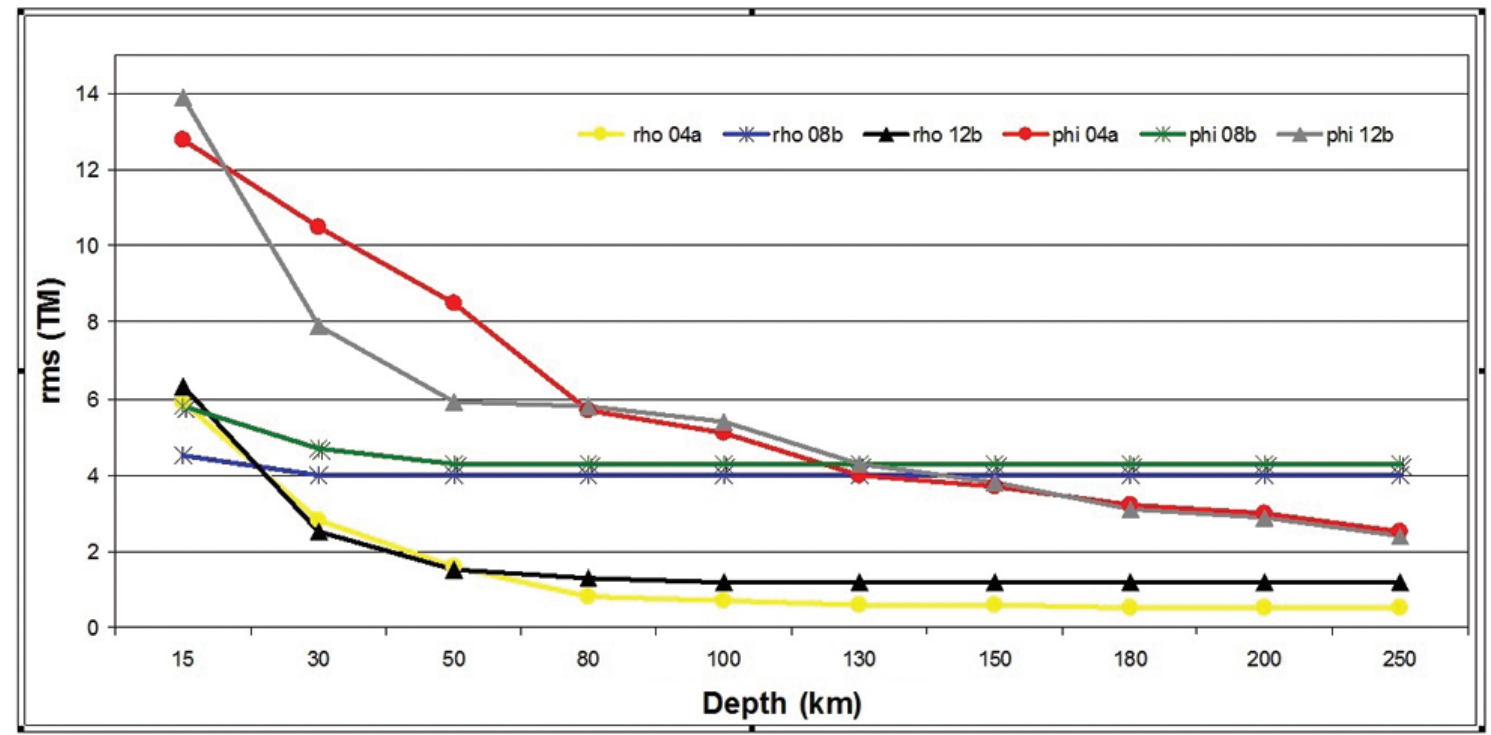

Figure $\mathbf{6}$ - RMS variation as a function of the depth of the perfect conductor and resistor for the apparent resistivity and phase of the TM mode at the stations $04 a, 08 b$ and $12 b$. Note that, to facilitate the visualization of the results, the depth axis is not evenly spaced.

generated by the models of Figures 2 and 4 using the empirical data of 3 representative stations of the profile (shown only for TM mode). The presence of the conductor alters significantly the fitting of the theoretical and experimental data of both stations (04a and $12 b$ ). This means that the maximum sensitivity depth of the data for these stations is deeper than the depth where the perfect conductor is found $(30 \mathrm{~km})$. On the other hand, under station 08b, the presence of the conductor body does not affect the theoretical curve, an indication that the sensitivity depth is lower than $30 \mathrm{~km}$. Another aspect to consider in Figure 5 is that the effect of the conductor is sensed before (shorter periods) in the phase than in the apparent resistivity. At station 12b, the phase changes at $1 \mathrm{~s}$ while the separation in the apparent resistivity appears at 10s. This is due to the fact that the phase is more sensitive to the transitions of conductivity than the apparent resistivity and, consequently, more detectable at shorter periods (the phase is related to the logarithmic derivative with the conductor placed of resistivity; Weidelt, 1972).

The procedure was repeated with the conductor placed at different depths in the interval between 15 and $250 \mathrm{~km}$. As described above, the sensitivity depth of the model was determined for each station comparing the RMS of the fitting of the experimental and theoretical data produced by models using the perfect conductor at different depths. Figure 6 shows the variation of the RMS of the model as a function of the depth of the conductor for the TM apparent resistivity and phase at the 3 stations shown in Figure 5. At the maximum depth of $250 \mathrm{~km}$, RMS is identical to that obtained by the model of Figure 2 in all stations. The RMS remaining constant at lower depths indicates that the data are not sensitive to the conductor inserted in the model. On the other hand, a changing RMS indicates that the data become sensitive to the conductor and, therefore, the deepest limit of sensitivity of 
the model is reached. The results show that the fitting of station 04a is affected when the conductor is placed at depths lower than $150 \mathrm{~km}$ for the apparent resistivity and lower than $200 \mathrm{~km}$ for the phase, while for $12 \mathrm{~b}$, the depths are $180 \mathrm{~km}$ (apparent resistivity) and $200 \mathrm{~km}$ (phase). For station 08b, the phase shows sensitivity to the resistor at $30 \mathrm{~km}$ while apparent resistivity only at $15 \mathrm{~km}$.

Similar analysis were performed for all stations and both EM wave propagation modes, TE and TM. Also, the technique was tested to evaluate regions of the model with high conductivity in the mid-upper crust (case of the Jatobá Basin), with the insertion of a high-resistivity body ( $10^{8} \mathrm{ohm} . \mathrm{m}$ ) at different depths under the stations affected by such structure. The results obtained for the depth from which the experimental data are sensitive to the perfect conductor and resistor, are shown in Table 1. It is observed that, in general, the TM mode reaches higher depths compared to the TE mode and the phase higher depths than the apparent resistivity. The occurrence of high conductivity in the upper crust of the Jatobá Basin (stations 07b to 08b) limits significantly the propagation of the EM signal, which reaches neither the inferior crust nor the upper mantle in this region.

Table 1 - Depth at which the data detects the presence of the perfect conductor for different stations and MT transfer functions.

\begin{tabular}{|c|c|c|c|c|}
\hline $\begin{array}{c}\text { Station } \\
\text { MT }\end{array}$ & $\begin{array}{c}\phi T M \\
(\mathrm{~km})\end{array}$ & $\begin{array}{r}\phi T E \\
(\mathrm{~km})\end{array}$ & $\begin{array}{c}\rho T M \\
(\mathrm{~km})\end{array}$ & $\begin{array}{l}\rho T E \\
(\mathrm{~km})\end{array}$ \\
\hline $00 \mathrm{a}$ & 200 & 150 & 200 & 150 \\
\hline $01 a$ & 200 & 200 & 200 & 150 \\
\hline 01b & 200 & 150 & 180 & 130 \\
\hline 02a & 200 & 200 & 200 & 50 \\
\hline $02 b$ & 200 & 200 & 200 & 50 \\
\hline 03a & 200 & 150 & 200 & 100 \\
\hline 03b & 200 & 200 & 180 & 80 \\
\hline 04a & 200 & 150 & 150 & 100 \\
\hline 04b & 200 & 200 & 150 & 50 \\
\hline 05a & 200 & 200 & 80 & 80 \\
\hline 05b & 200 & 200 & 80 & 50 \\
\hline 06a & 200 & 200 & 80 & 50 \\
\hline $06 \mathrm{~b}$ & 200 & 80 & 80 & 50 \\
\hline $07 a$ & 100 & 100 & 80 & 50 \\
\hline $07 \mathrm{~b}$ & 30 & 15 & 15 & 15 \\
\hline $08 \mathrm{a}$ & 30 & 15 & 15 & 15 \\
\hline $08 \mathrm{~b}$ & 30 & 15 & 15 & 15 \\
\hline $08 \mathrm{C}$ & 200 & 180 & 100 & 30 \\
\hline 09b & 200 & 150 & 180 & 30 \\
\hline $10 \mathrm{a}$ & 200 & 200 & 200 & 180 \\
\hline $10 \mathrm{~b}$ & 200 & 80 & 200 & 30 \\
\hline $12 a$ & 200 & 180 & 200 & 80 \\
\hline $12 b$ & 200 & 150 & 180 & 80 \\
\hline
\end{tabular}

\section{COMPARISON OF THE RESULTS OF EMPIRICAL AND HEURISTIC TECHNIQUES}

The maximum sensitivity depth of the 2D model to the experimental data is given in the heuristic technique by the maximum depth obtained from the Niblett-Bostick transform of the TM mode while in the empirical technique it is given by the deepest depth of sensitivity to a perfect conductor, derived from the phase of TM mode. These are the deepest depths at which the data represent the subsurface conductivity distribution.

Figure 7 compares the depth intervals reached by the MT signals at all stations for both techniques. It can be noted that the empirical technique provides deeper depths of sensitivity of the model, an indicator that the estimates given by the heuristic technique are conservative. Also, the results given by the empirical technique are laterally more homogeneous, eliminating some local oscillations generated by Niblett-Bostick transform. This result may be explained by the fact that the empirical technique considers the effect of a $2 \mathrm{D}$ model of conductivity distribution while the heuristic technique is based on a $1 \mathrm{D}$ transform. Due to the diffuse propagation of the EM wave, the signal at a certain frequency under a station is not affected only by the vertical distribution of conductivities as assumed in a $1 \mathrm{D}$ model, but also by what happens laterally as assumed in a 2D model. Therefore, the depths given by the empirical techniques are more appropriate than those derived from the heuristic technique.

The data have sensitivity to the maximum depth shown in the 2D model of Figure 2 for practically all stations of the profile. The exceptions are the stations located over the Jatobá Basin, where the strong conductor situated in the upper crust under the basin dampens the EM signal so as not to allow to obtain information of the lower crust and mantle at the measured frequency range.

These maximum depths refer to one of the propagation modes of the EM wave. In this case, the conductivity model have meaning only if the conductivity distribution is $1 \mathrm{D}$ (conductivity varies only as function of depth). Except for very specific cases (thick sedimentary basins or large mantle depths), 1D situations are rare in lithospheric studies. In the case of a 2D conductivity distribution, information from both propagation modes of the EM wave is necessary to verify the lateral variation of the structures. The deepest depth of sensitivity defined by the TE mode is used herein as the limit for interpretation of the 2D model since it is generally more sensitive to the perfect conductor or resistor at lower depths when compared to the TM mode.

Figure 8 shows a comparison of the depths reached by the MT signals for the TE mode at all stations. The results are quite similar to those of the Figure 7 for the whole profile. 


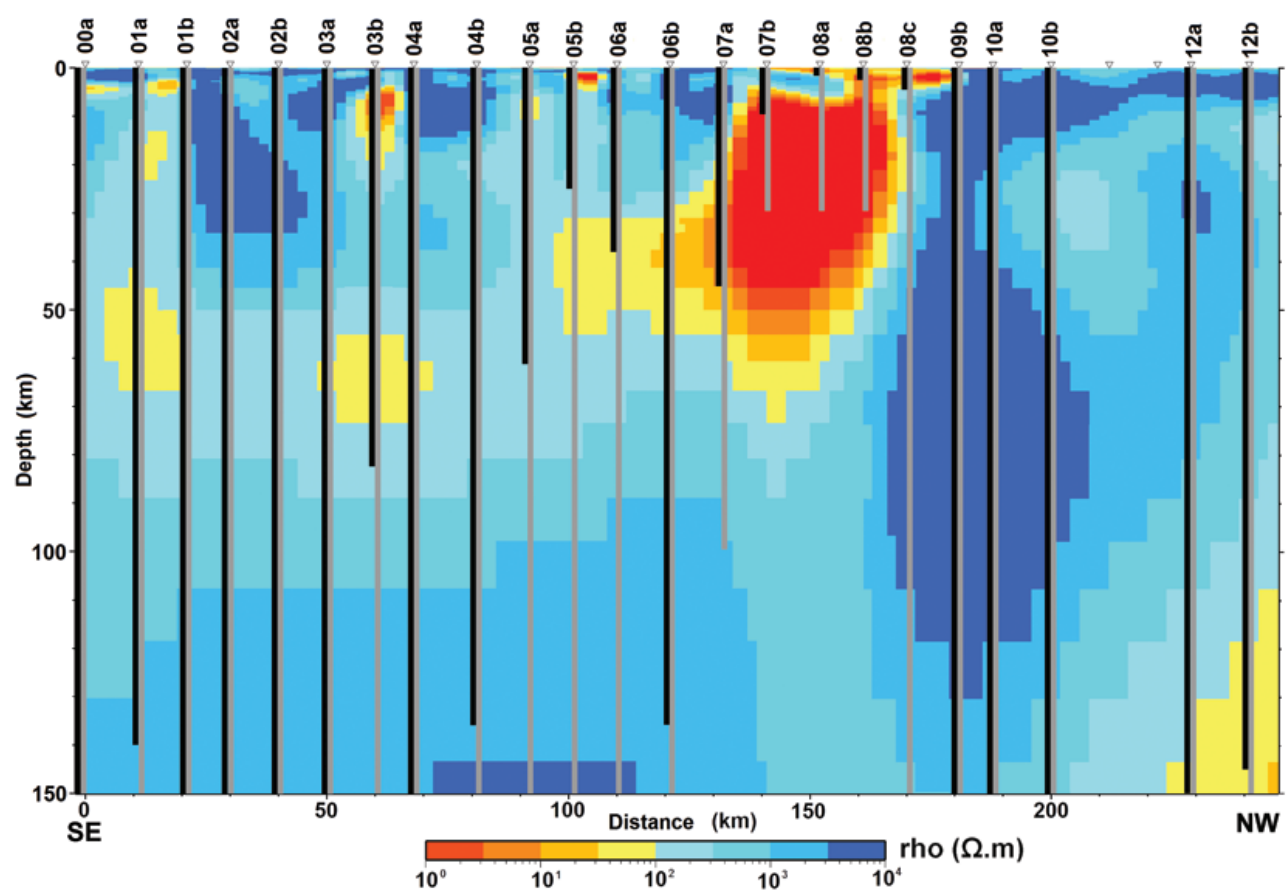

Figure 7 - Comparison of maximum sensitivity depths of the 2D model (Fig. 2), given by the heuristic (black) and empirical (grey) techniques. The heuristic technique uses the depth given by the Niblett-Bostick transform in the TM mode while the empirical technique uses the effect of the perfect resistor or conductor on the TM mode phase.

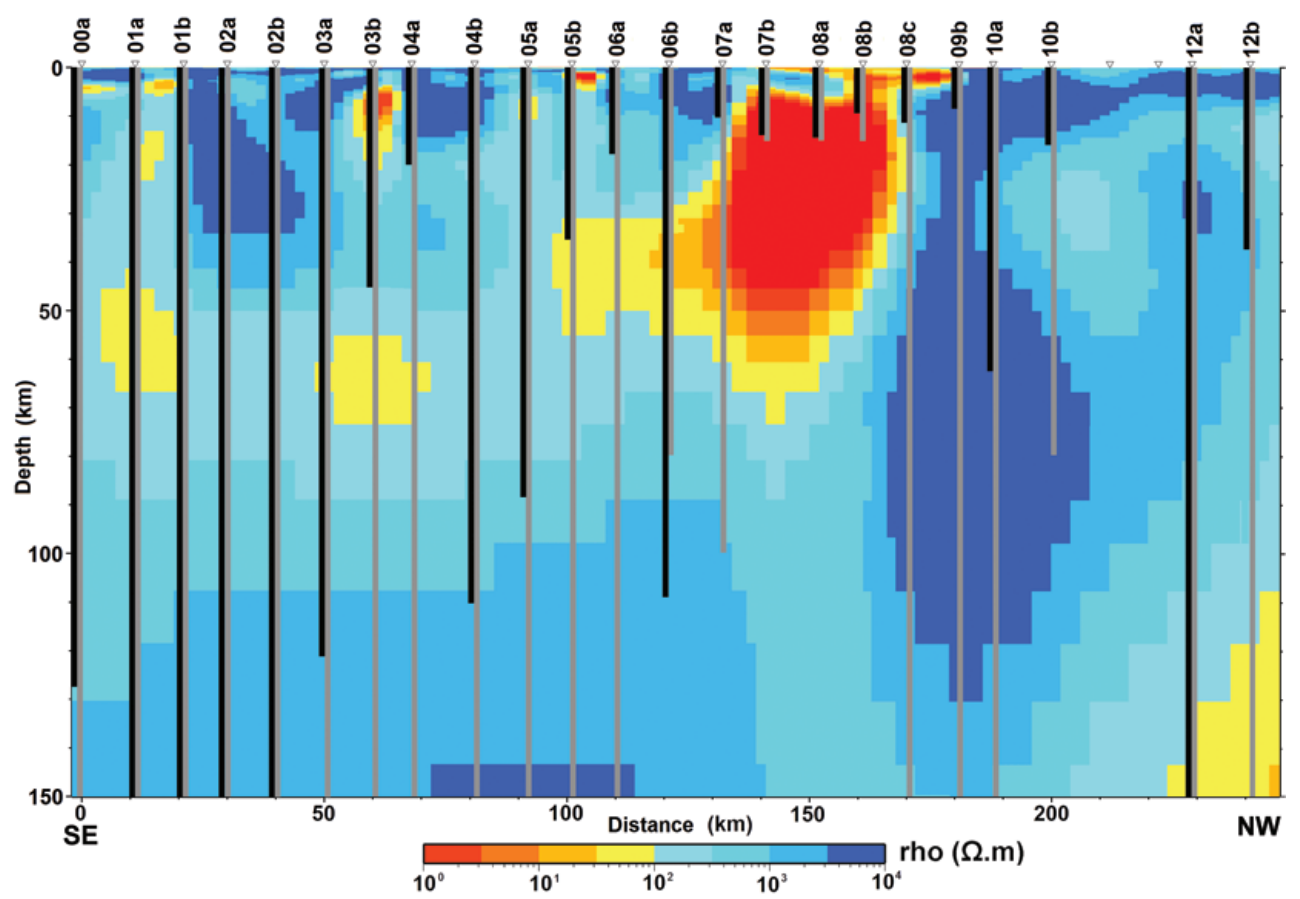

Figure 8 - The same as Figure 7, using the Niblett-Bostick transform in the TE mode to show the depth obtained by the heuristic technique and the effect of the perfect resistor or conductor on the TE mode phase to show the empirical technique. 


\section{CONCLUSIONS}

The empirical technique proposed here is very simple. It is based on the introduction of a laterally unlimited, perfect conductor or resistor at different depths of a 2D conductivity distribution model to verify how it affects the fitting of the data by forward calculation using the same program used for data inversion. It can be used to investigate the deepest depth of sensitivity of the model to the propagation of the EM signal through the effect on the phase of the TM mode, as well as to define the limit depth of 2D model interpretation, with the effect on the phase of the TE mode.

The technique presented to estimate the maximum depth limits interpretation of the geoelectrical models has advantages over the heuristic techniques presented in the literature (particularly, the Niblett-Bostik transform). This is due to the fact that it uses the conductivity model derived from the 2D inversion to estimate the maximum depth of reliability of the model with respect to the experimental data. The comparison of the results of both methodologies for a real situation shows a broadly similar behavior for varying depths. However, the heuristic methodology is generally more conservative in the depth definition and provides lateral variations between stations that are not compatible with the diffusive process of EM waves propagation.

The results obtained for the 2D conductivity model of the SE region of the Borborema Province show that the model can be interpreted to the maximum depth show in Figure $2(150 \mathrm{~km})$ across the southern and northern portion of the profile, including the Sergipano Belt, the Pernambuco-Alagoas Block, and the Alto Moxotó terrain. On the other hand, the signal under the Jatobá Basin only penetrates the upper crust (up to about $15 \mathrm{~km}$ ).

\section{ACKNOWLEDGMENTS}

The authors are thankful to INCT-ET, for the financial support (Process CNPq 573.713/2008-1), and to UnB and INPE, that allowed for the completion of the academic work. Critical reviews by two anonymous reviewers contributed to the final version of the manuscript.

\section{REFERENCES}

ALMEIDA FFM, HASUI Y, BRITO NEVES BB \& FUCK R. 1981. Brazilian structural provinces: an introduction. Earth Sci. Rev., 17: 1-29.

BAHR K. 1988. Interpretation of the magnetotelluric impedance tensor: regional induction and local telluric distortion. J. Geophys., 62: 119127.

BERDICHEVSKY MN \& DMITRIEV VI. 2002. Magnetotellurics in the Context of the Theory of III-posed Problems. SEG, Tulsa, 215 pp.
BOSTICK FX. 1977. A simple almost exact method of MT analysis. In: Workshop on Electrical Methods in Geothermal Exploration, Salt Lake City. U.S. Geol. Survey contract no. 14080001-8-359.

DE GROOT-HEDLIN C \& CONSTABLE SC. 1990. Occam's inversion to generate smooth, two-dimensional models from magnetotelluric data. Geophysics, 55: 1613-1624.

DENNIS ZR, MOORE DH \& CULL JP. 2011. Magnetotelluric survey for undercover structural mapping in central Victoria. Australian J. Earth Sci., 58: 33-47.

EGBERT GD. 1997. Robust multiple-station magnetotelluric data processing. Geophys. J. Inter., 130: 475-496.

EVANS RL, JONES AG, GARCIA X, MULLER M, HAMILTON M, EVANS S, FOURIE CJS, SPRATT J, WEBB S, JELSMA H \& HUTCHINS D. 2011. Electrical lithosphere beneath the Kaapvaal craton, southern Africa. J. Geophys. Res., 116: B04105, doi: 10.1029/2010JB007883.

FERGUSON IJ, CRAVEN JA, KURTZ RD, BOERNER DE, BAILEY RC, WU $X$, ORELLANA MR, SPRATT J, WENNBERG G \& NORTON M. 2005. Geoelectric response of Archean lithosphere in the western Superior Province, central Canada. Phys. Earth Planet. Inter., 150: 123-143.

GRO0M RW \& BAILEY RC. 1989. Decomposition of magnetotelluric impedance tensor in the presence of local three-dimensional galvanic distortion. J. Geophys. Res., 94: 1913-1925.

HAMILTON MP, JONES AG, EVANS RL, EVANS S, FOURIE CJS, GARCIA $X$, MOUNTFORD A \& SPRATT JE. 2006. Electrical anisotropy of South African lithosphere compared with seismic anisotropy from shear-wave splitting analyses. Phys. Earth Planet. Inter., 158: 226-239.

JONES AG. 1983. On the equivalence of the Niblett and Bostick transformations in the magnetotelluric method. J. Geophys., 53: 72-73.

JONES AG. 2006. Electromagnetic interrogation of the anisotropic Earth: Looking into the Earth with polarized spectacles. Phys. Earth Planet. Inter., 158: 281-291.

MEDEIROS VC. 2004. Evolução geodinâmica e condicionamento estrutural dos terrenos Piancó-Alto Brígida e Alto Pajeú, domínio estrutural da zona transversal, NE do Brasil. Doctorate thesis on Geodynamics Programa de Pós-Graduação em Geodinâmica e Geofísica, Universidade Federal do Rio Grande do Norte, 2004. 199 pp.

MIENSOPUST MP, JONES AG, MULLER MR, GARCIA X \& EVANS RL. 2011. Lithospheric structures and Precambrian terrane boundaries in northeastern Botswana revealed through magnetotelluric profiling as part of the Southern African Magnetotelluric Experiment. J. Geophys. Res., 116: B02401, doi: 10.1029/2010JB007740.

NIBLETT ER \& SAYN-WITTGENSTEIN C. 1960. Variation of electrical conductivity with depth by the magneto-telluric method. Geophysics, 25 998-1008.

OLIVEIRA RG, ACCIOLY ACA \& SANTOS CA. 2010. Magnetometria, gamaespectrometria e gravimetria da região de junção dos terrenos 
Alto Moxotó, Rio Capibaribe e Pernambuco-Alagoas da Província Borborema. In: Simpósio Brasileiro de Geofísica, 4, 2010, Brasília. Proceedings... Brasília: SBGf, 2010. CD-ROM.

PARKER RL. 1982. The existence of a region inaccessible to magnetotelluric sounding. Geophys. J. Roy. Astr. Soc., 68: 165-170.

REID JE \& MACNAE JC. 1999. Doubling the effective skin depth with a local source. Geophysics, 64: 732-738.

SANTOS ACL. 2012. Imageamento magnetotelúrico de estruturas da litosfera na porção SE da Província Borborema. Doctorate thesis on Geology - Programa de Pós-Graduação em Geologia, Universidade de Brasília, 2012. 159 pp.
SIMPSON F \& BAHR K. 2005. Practical Magnetotellurics. Cambridge University Press, Cambridge, 270 pp.

SIRIPUNVARAPORN W \& EGBERT G. 2000. An efficient data-subspace inversion for two-dimensional magnetotelluric data. Geophysics, 65: 791-803.

SPIES BR. 1989. Depth of investigation in electromagnetic sounding methods. Geophysics, 54: 872-888.

WEIDELT P. 1972. The inverse problem of geomagnetic induction. J. Geophys., 38: 257-289.

Recebido em 26 dezembro, 2011 / Aceito em 6 agosto, 2012

Received on December 26, 2011 / Accepted on August 6, 2012

\section{NOTES ABOUT THE AUTHORS}

Andréa Cristina Lima Santos. Graduated in Geography (2001) and Geology (2010) from the Universidade do Estado do Rio de Janeiro, MSc (2007) and PhD (2012) in Geology from the Universidade de Brasília. Experience in the fields of Geosciences, working especially with the following topics: magnetotelluric surveys, gamma spectrometry and magnetometry.

Antônio Lopes Padilha. Graduated in Physics (1978), MSc (1982) and PhD (1989) in Geophysics from the Universidade de São Paulo. Currently, he is a senior researcher at the Instituto Nacional de Pesquisas Espaciais. Conducts research in the fields of Geosciences, with emphasis on terrestrial electromagnetic induction, working with the GDS and magnetotelluric methods, and geomagnetism, studying geomagnetic variations at low latitudes.

Icaro Vitorello. Graduated in Geosciences (1972), MSc (1975) and PhD (1978) in Geophysics at the Department of Geological Sciences, University of Michigan - Ann Arbor (MI, USA). Currently, works at Instituto Nacional de Pesquisas Espaciais where started in 1980. Has extensive experience in the field of Geosciences, with emphasis on terrestrial electromagnetic induction, working mainly with research and applications of the methods of magnetotelluric and geomagnetic surveys, in tectonic studies.

Marcelo Banik de Pádua. Graduated in Physics (1996) from the Universidade de São Paulo, MSc (2000) and PhD (2004) in Spatial Geophysics from the Instituto Nacional de Pesquisas Espaciais. Currently, is a technologist at Instituto Nacional de Pesquisas Espaciais. Has experience in geomagnetism, working mainly with magnetotelluric and GDS surveys, and processing of geomagnetic data.

Augusto César Bittencourt Pires. Graduated in Geology (1968) from the Universidade Federal do Rio de Janeiro and PhD (1975) and post-doctorate (1989) in Geophysics at Colorado School of Mines. Currently, is a professor at Universidade de Brasília. Has experience in Geosciences, with emphasis in Geophysics, working with applied Geophysics, and the integration of geosciences and mineral prospection data. 